\title{
RETENTION OF ELEMENTAL MERCURY IN FLY ASHES IN DIFFERENT ATMOSPHERES
}

\author{
M.A. López-Antón, M. Díaz-Somoano, and M.R. Martínez-Tarazona* \\ Instituto Nacional del Carbón (CSIC), C/ Francisco Pintado Fé, n² 26, 33011 Oviedo, \\ Spain
}

*Corresponding author. Tel.: +34 985118988. Fax.: +34 985297662

E-mail: rmtarazona@incar.csic.es 


\begin{abstract}
Mercury is an extremely volatile element, which is emitted from coal combustion to the environment mostly in vapour phase. In order to avoid the environmental problems that the toxic species of this element may cause, control technologies for the removal of mercury are necessary. Recent research has shown that certain fly ash materials have an affinity for mercury. Moreover, it has been observed that fly ashes may catalyse the oxidation of elemental mercury and facilitate its capture. However, the exact nature of Hg-fly ash interactions is still unknown and mercury oxidation through fly ash needs to be investigated more thoroughly. In this work the influence of gas atmosphere on the retention of elemental mercury on fly ashes of different characteristics was evaluated. The retention capacity was estimated comparatively in inert and in two gas atmospheres containing species present in coal gasification and coal combustion. Fly ashes produced in two Pulverized Coal Combustion plants (PCC), produced from coals of different rank (CTA and CTSR), and a fly ash produced in a Fluidized Bed Combustion plant (CTP) were used as raw materials. The mercury retention capacity of these fly ashes was compared with the retention obtained in different activated carbons. Although the capture of mercury is very similar in the gasification atmosphere and in $\mathrm{N}_{2}$, it is much more efficient in a coal combustion retention being greater in fly ashes from PCC than from FBC plants.
\end{abstract}

Keywords Mercury, coal combustion, fly ashes 


\section{INTRODUCTION}

Mercury has received considerable attention due to its high toxicity, a tendency to bio-accumulate, and a series of difficulties that impede its control. This element is often found as a trace contaminant in coal (1). When coal is used in processes for power generation, the combination of elevated temperatures and the volatility of mercury and its compounds, enable the mercury to enter the combustion gas exhaust stream

Coal-fired utility boilers were identified in the "Mercury Study Report" Published in 1997 by the U.S. EPA (Environmental Protection Agency), as the largest single anthropogenic source of mercury emissions. As a consequence, in December 2000, the EPA announced its intention to regulate Hazardous Air Pollutants (HAPs) from coal-fired electrical generating stations and on March 2005 issued the Clean Air Mercury Rule to permanently cap and reduce mercury emissions from coal-fired power plants. This rule makes the United States of America the first country in the world to regulate mercury emissions from utilities (2).

In Europe, mercury emission from coal combustion is also becoming a matter of growing interest. Some European countries such as Germany, Italy, and Switzerland have already adopted national regulations on mercury emissions, moreover, in April, 2001, the European Commission (EC) approved the protocol on heavy metals in order to reduce the emissions of metals that are prone to long-range transboundary atmospheric transport and are likely to have adverse effects on human health and the environment. The EC published in 2004 a consultation document inviting comments by stakeholders and other related persons in the field. This document identified large-scale coal combustion units as the largest emitters of mercury compounds into the air. In 
January 2005, the Commission adopted a mercury strategy that envisages a number of measures to protect the health of citizens and their environment (3).

At present, there is no universally accepted Hg control technology for coal-fired utilities, and the incorporation of the technologies already in use in waste incineration plants could enhance the cost of the process considerably. Several solid materials, such as activated carbons, calcium based sorbents, and zeolites, have been considered as sorbents for mercury control in flue gases from coal combustion (4-7). Experience in the use of such sorbents has been gained from solid waste incinerators, in which mercury species in gases are typically removed by using hydrated lime and activated carbons (8). In general, in coal combustion and waste incineration, hydrated lime can be considered as a good sorbent for the retention of $\mathrm{Hg}(\mathrm{II})$, mainly $\mathrm{HgCl}_{2}$ (9). For the retention of $\mathrm{Hg}^{0}$, sulphur or iodine- impregnated activated carbons (10-12) have proven to be the best option, although this method is usually very costly.

Recent research has focused on the capacity of certain fly ashes to capture mercury and their influence on mercury speciation in the process. It is well known that fly ashes may retain different proportions of mercury. The amounts may vary considerably for different coals and plants. More specifically it has been observed that the unburned material present in fly ash shows a considerable retention capacity for retaining mercury (13-18). According to this research, carbonaceous particles present in fly ashes are capable of retaining mercury species in different proportions depending on their characteristics and the process conditions. Various studies on fly ashes suggest that retention capacity depends not only on their unburned content, but also on their surface area, morphology and petrographic characteristics $(7,13,19-20)$. However, the exact nature of Hg-fly ash interactions, as well as the role of the inorganic components is still unknown and needs to be investigated more thoroughly. The aim of the present work 
was to evaluate the variables that influence the retention of elemental mercury in fly ashes in coal combustion and coal gasification processes and to identify the species responsible for mercury capture. To achieve this goal, the behaviour of three fly ashes of different characteristics and two activated carbons were compared. The work has mainly focused on evaluating the possible oxidation of elemental mercury on the surface of fly ashes. The work was focused on the influence of gas atmosphere on mercury capture and on how the gas composition influences this capture in fly ashes. The two main variables studied were: i) the nature and characteristics of the sorbents (fly ashes mainly composed of inorganic constituents with a small amount of unburned particle content (LOI), and activated carbons which are mainly made up of carbon having a different but lower mineral content) and ii) the gas atmosphere (inert, a gas composition containing species present in coal gasification and a gas composition containing species present in coal combustion).

\section{EXPERIMENTAL METHODS AND CONDITIONS}

Three fly ash samples (CTA, CTSR and CTP) and two activated carbons (CA and RB3) were used as mercury sorbents. CTA was obtained in a pulverized coal power plant (PCC) in which mixtures of coal containing anthracites were burned, whereas CTSR was sampled from a PCC plant in which mixtures of coal mainly containing bituminous coals were used. The third fly ash (CTP) was taken from a fluidised bed combustion plant (FBC) that burns mixtures of coal and coal wastes with a high mineral matter content, using limestone in the bed. The activated carbon CA was prepared by physical activation of a semi-coke obtained by the pyrolysis of a coal of high sulphur content (21). RB3 is a commercial activated carbon (Norit RB3). The fly ashes were 
used in their original sizes, and the activated carbons were ground to a particle size of 0.2-0.5 mm. These materials were characterized by various methods before being used as sorbents. Atomic absorption spectrometry (AAS) was used to determine the elemental composition. The morphological study was carried out by Scanning Electron Microscopy (SEM). The crystalline species were identified in the fly ashes and in the mineral matter of the activated carbons obtained by Low Temperature Ashing (LTA), by X-ray diffraction (XRD). The BET surface area was determined by volumetric adsorption of nitrogen at $77 \mathrm{~K}$. Thermodynamic equilibrium models were used to theoretically predict the composition of the chemical species in gas phase with HSCChemistry 4.0 software.

The experimental device used for the retention experiments consisted of a glass reactor fitted to an internal and external tube and heated by two furnaces (Figure 1). $\mathrm{Hg}^{0}(\mathrm{~g})$ in the gas atmosphere was obtained by the evaporation of solid $\mathrm{Hg}^{0}$. The evaporation temperature of mercury was optimised in order to ensure a continuous and constant amount of trace elements in the combustion atmosphere, $0.2 \mathrm{mg} \mathrm{min}^{-1}$. This high concentration of mercury was used to achieve the maximum retention capacity of sorbents in a short time. The evaporation temperature was $190^{\circ} \mathrm{C}$. The sorbent and the element source were placed inside the internal tube but heated separately in the two furnaces. The temperature of the sorbent bed was $120^{\circ} \mathrm{C}$. Synthetic gas mixtures, with a gas composition containing species present in coal gasification and a gas composition containing species present in coal combustion, were passed through the reactor (Table 1). These gas mixtures carried the element compound in vapor phase through the sorbent bed at a flow rate of $0.5 \mathrm{~L} \mathrm{~min}^{-1}$. The mercury concentrations in gas phase were between 0.12 and $0.40 \mu \mathrm{g} \mathrm{ml}^{-1}$ and the contact time was approximately 0.6 seconds, similar to other works where they were between 0.7 and 2 seconds (15). The element 
that was not retained in the sorbent bed was captured in two impingers containing $4 \%$ $\mathrm{KMnO}_{4}+10 \% \mathrm{H}_{2} \mathrm{SO}_{4}$ and $\mathrm{HNO}_{3} 0.5 \mathrm{~N}$. The sorbent bed was prepared by mixing $1 \mathrm{~g}$ of fly ash or activated carbon with $3 \mathrm{~g}$ of sand. The bed was $2.5 \mathrm{~cm}$ in diameter and $1.1 \mathrm{~cm}$ in height. The mercury retained in the sorbents was determined by cold vapour atomic absorption (CV-AA) after mercury extraction with $60 \%(\mathrm{v} / \mathrm{v}) \mathrm{HNO}_{3}$ in a microwave oven 500w/4 min. For low mercury concentrations an Automatic Mercury Analyser (AMA) was used to determine the mercury content of the solid directly. Blank experiments were carried out by using only sand as sorbent bed. Sorption capacity (milligrams of element per g of sorbent) and efficiency (percentage of element retained) were then evaluated. To determine maximum retention capacity (MRC), a series of experiments were conducted, in which the quantity of the element was gradually increased until the sorbent was saturated.

\section{RESULTS AND DISCUSSION}

Two different groups of very different sorbents were evaluated in this work. Fly ashes are a mixture of inorganic components mainly made up of aluminosilicates and metal oxides at different stages of transformation, and contain a small proportion of organic matter (unburned coal particles), determined as LOI (loss on ignition) in Table 2. The activated carbons are mainly carbonaceous materials made up of organic matter with a small mineral content expressed as \% ash (percentage of ashes) in Table 2. Differences may be observed between the fly ashes and between the two activated carbons (Tables 2-3). These differences, however, are more significant in the case of the carbons. The commercial Norit RB3 has an ash content of $6 \%$, whereas the activated 
carbon prepared by activation of a pyrolyzed subbituminous coal (CA), has a $30 \%$ ash content (21). The composition of the inorganic components of the fly ashes calculated as percentages of oxides is shown in Table 3, and is similar for the three samples. The main difference was the greater content of $\mathrm{Ca}$ and S present in the CTP, the fly ash obtained from the FBC plant (Table 3). Regarding the ash composition of the two activated carbons, CA has the highest iron content. In fact it is even higher than that of the fly ashes. Also worth noting are the relatively similar Ca concentration in CA and CTA and the fact that CTP is the sample with the largest Ca content. The mineral composition, as estimated by XRD, differs considerably for each fly ash. While in CTA the only crystalline phase was quartz, in CTSR aluminosilicates, $\left(\mathrm{Al}_{6} \mathrm{Si}_{2} \mathrm{O}_{13}\right)$ were also detected. In CTP the mineral matter was less altered and illite, calcite, anhydrite and hematite together with quartz were identified. The minerals detected in the activated carbons were mainly silica oxides and carbonates. SEM characterization of the fly ash revealed that the fly ash samples from the coal-pulverized power plant (CTA and CTSR) are mainly made up of glassy microspheres of different sizes (Figure 2a), while the fly ash from the fluidized bed boiler shows a completely different morphology, the particles being composed mainly of an irregular material (Figure 2b). SEM observation of the mineral matter of activated carbon CA showed that some of the minerals originally present in the pyrolyzed coal had been altered (Figure 3a), whereas other particles remained unaltered (Figure 3b). Although fly ashes are non-porous solids as demonstrated from the $\mathrm{N}_{2}$ adsorption isotherms (type II), the highest values for surface area were found in CTSR $\left(9.4 \mathrm{~m}^{2} \mathrm{~g}^{-1}\right)$, the surface areas of CTP and CTA being 6.7 and $1.6 \mathrm{~m}^{2} \mathrm{~g}^{-1}$, respectively. These differences in surface area, however, are not significant compared to activated carbons (CA:310 $\mathrm{m}^{2} \mathrm{~g}^{-1}$; RB3:1183 $\mathrm{m}^{2} \mathrm{~g}^{-1}$ ). 
The retention experiments were carried out by passing the mercury obtained from the evaporation of elemental mercury $\left(\mathrm{Hg}^{\circ}\right)$, through the sorbent. In order to evaluate the mercury composition in gas phase, a theoretical assessment of the equilibrium composition of the mercury species at $120^{\circ} \mathrm{C}$ (temperature of the sorbent bed), was calculated for the three gas atmospheres employed in the experiments, using thermodynamic data at the equilibrium. From these calculations it can be inferred that when $\mathrm{Hg}^{0}$ is the source of the element in a combustion atmosphere, both $\mathrm{Hg}(\mathrm{g})$ and $\mathrm{HgO}(\mathrm{g})$ may be present in proportions close to 50\%. In the gasification atmosphere, $\mathrm{Hg}\left(\mathrm{CH}_{3}\right)_{2}$ (g) would be a stable species, if equilibrium could be achieved. However, when the flue gases were analysed at the outlet by gas chromatography, no $\mathrm{Hg}\left(\mathrm{CH}_{3}\right)_{2}$ (g) was identified. As might be expected, the theoretical study carried out in the $\mathrm{N}_{2}$ atmosphere confirmed that the only mercury species present in gas phase in this inert atmosphere was $\mathrm{Hg}(\mathrm{g})$.

The experimental procedure was designed to evaluate the retention capacities of different fly ashes and activated carbons using higher concentrations of mercury than might be expected in a coal. The mercury retained was determined by analysing the sorbent post-retention after passing different amounts of elemental mercury through the sorbent bed. The quantity of element retained was plotted against the quantity of element passed through the sorbent in a discontinuous approach. If an approximate estimation is made, two parameters that are useful for comparing the behaviour of the sorbents can be inferred. One is efficiency, defined as percentage of element retained $(\% \mathrm{E})$ and the other maximum retention capacity (MRC), which represents the saturation level of the sorbent (Figures 4-6). The values for \%E and MRC are presented in Table 2. Efficiency was calculated as the average of several determinations (4-8) and the confidence limit of the results is given as the standard deviation. The possible 
condensation of mercury species in the sorbent bed was evaluated by using only the inert material (sand) as sorbent. No significant amount of mercury was retained in this material in the experimental conditions of this study (Table 2).From the results in Table 2 it can be seen that unlike the activated carbons, the fly ashes show different retention capacities and efficiencies in the combustion and gasification atmospheres. Retention capacities on the fly ashes in the gasification atmosphere are lower than in that of combustion, but they are similar to that observed in $\mathrm{N}_{2}$. In the combustion atmosphere the retention capacity on the CTSR fly ash reached a value of $25 \mathrm{mg} \mathrm{g}^{-1}$ compared to 3.94 and $3.71 \mathrm{mg} \mathrm{g}^{-1}$ in the gasification and inert atmospheres. These differences are even more significant in the CTA fly ash sample. Variations were also observed in CTP but the low retentions in this fly ash do not allow us to infer that there is a higher retention in the combustion atmosphere than in that of gasification as in the case of CTA and CTSR. The different values obtained in the gasification and $\mathrm{N}_{2}$ atmospheres are due to the uncertainty of the experimental results and the MRC in both atmospheres may be considered identical in the three fly ashes. In contrast to fly ash retention capacity the amount of mercury retained in the activated carbons was similar for combustion and gasification. In the combustion atmosphere, the MRC in the CA and the RB3 carbons was lower than in the CTA and CTSR fly ashes, but efficiency was higher Table 2. This may indicate that the surface area of the sorbent is not the main factor influencing retention, even though it may control the kinetics of the process (Figures 46). Retention capacity is significantly higher in fly ashes than in activated carbons only in the combustion atmosphere where oxidation may occur. In the gasification atmosphere where this oxidation can not take place the higher retention capacities are obtained for the activated carbon of highest surface area. A relationship between the carbonaceous material content and mercury retention can be seen when the fly ashes are 
compared with one another and also when the two activated carbons are compared. In both cases, mercury retention increases with a higher carbon content. However, in general, the fly ashes with the highest carbon content have the greatest mercury retention capacity. The results for gasification do not follow the same rule, because in this case the differences between retention in the fly ashes and activated carbons are lower, efficiency being higher in the samples with the highest surface area.

The explanation for the different behaviour of mercury in fly ashes but not in the activated carbons in the combustion and gasification atmospheres is to be found in the characteristics which are common to all of the fly ashes and differ from the carbons. The fact that similar mercury retentions in fly ashes were obtained in the gasification and inert atmospheres, where $\mathrm{Hg}^{\circ}$ (g) was the stable species in gas phase, and the fact that no differences were observed between the retentions in the combustion and gasification atmospheres when activated carbons were used as sorbents, suggest that some of the fly ash components, which are not present in the activated carbons, could favour the oxidation of $\mathrm{Hg}^{0}$ to $\mathrm{Hg}(\mathrm{II})$. Oxidised mercury could be more efficiently captured on the fly ashes than elemental mercury. This hypothesis has been previously put forward (15). The oxidation of elemental mercury in a coal combustion atmosphere has been related to the presence of $\mathrm{HCl}$ in the gas atmosphere and to the formation of reactive $\mathrm{HgCl}_{2}$ (15), and even to the presence of $\mathrm{NO}$ and $\mathrm{NO}_{2}$ (22). However, in the conditions of this work the combustion atmosphere studied did deliberately not contain $\mathrm{HCl}, \mathrm{NO}$ or $\mathrm{NO}_{2}$. Other fly ash components, iron and calcium species among others, have also been suggested as possible factors responsible for mercury oxidation in fly ashes (15). The amount of iron content in the three fly ashes is similar and is maximum in CA carbon but no relation between this fact and mercury retention was observed. Moreover, CTP has the greatest calcium content and in this material mercury capture is 
the lowest. It should be noted that the nature of the mineral components as demonstrated by DRX and SEM, is different in the fly ashes from PCC, the fly ashes from FBC and activated carbons. In light of these considerations it could be inferred that the inorganic species in the materials used as sorbents may be determinant in mercury capture in a combustion atmosphere, where mercury oxidation is possible, even in the absence of $\mathrm{HCl}$, and NOx. Apparently the components of fly ashes obtained from PCC (minerals transformed at high temperature), are more effective in the oxidation process than the components of fly ashes obtained in FBC, which undergo less transformation than in PCC due to the lower temperatures of combustion.

Although mercury oxidation in fly ashes in a combustion atmosphere, and the subsequent capture of oxidized mercury were directly analyzed in the experimental conditions of this work, the different results obtained in the atmospheres used in the experiments and the comparison of fly ash behavior with that of activated carbons in the same conditions, may only be attributed to oxidation of mercury. When the sorbents used are fly ashes (mainly made up of inorganic materials), the retention capacity is significantly higher in a combustion than in a gasification and inert atmosphere, and when the sorbents are activated carbons (mainly made up of carbon material), the retention is similar in gasification and combustion. If the only variables are the material and the gas atmosphere the assumption that mercury can be oxidized in a combustion atmosphere that may be catalyzed by the inorganic components, but not by carbon in activated carbons is acceptable. Such oxidation did occur in the absence of $\mathrm{HCl}$.

\section{CONCLUSIONS}

The retention of mercury in the fly ashes studied is greatly influenced by the gas composition. The capture of mercury in these fly ashes is higher in a typical combustion 
atmosphere than in a coal gasification atmosphere unlike the case of activated carbons of different origin, where capture is similar for both atmospheres. The nature of the fly ashes is determinant in the control of mercury capture. The fly ashes obtained from PCC plants are more efficient in mercury retention than those obtained from FBC where the minerals do not undergo as much transformation.

\section{ACKNOWLEDGEMENTS}

This work was carried out with financial support from the Spanish Ministerio de Ciencia y Tecnología PN I+D+I (Project PPQ2001-2359-C02-02) and from the project ECSC (7220-ED/095)

\section{REFERENCES}

(1) Onei, B.T.; Tewalt, S.J.; Finkelman, R.B.; Akers, D.J. Fuel. 1999, 78, 47-54.

(2) U.S. Environmental Protection Agency, Mercury http://www.epa.gov/mercury

(3) http://europa.eu.int/comm/environment/chemicals/mercury/index.htm

(4) Felsvang, K.; Gleiser, R.; Juip, G.; Nielsen, K.K. Fuel Process. Technol. 1994, 39, 417-430.

(5) Krishnan, S.V.; Jozewicz, W.; Gullett, B.K. Proceedings of Solid Waste Management Thermal Treatment \& Waste to Energy Technologies Conference, USEPA/AEERL \& WMA, April 18-21: Washington, D.C., USA, 1995.

(6) Ghorishi, B.; Gullett, B.K. Waste Management Res. 1998, 16, 582-593.

(7) Hassett, D.J.; Eylands, K.E. Fuel. 1999, 78, 243-248.

(8) Gullett, B.K.; Ragnunathan, K. Energy Fuels. 1994, 8, 1068-1076.

(9) Krishnan, S.V.; Gullett, B.K.; Jozewicz, W. Environ. Prog. 1997, 16, 47-53.

(10) Vidic, R.D.; Liu, W. $24^{\text {th }}$ Biennal Conference on Carbon, American Carbon Society; 11-16 July: Charleston, South Carolina,1999; pp 754-755. 
(11) Jozewicz, W.; Krishnan, S.V.; Gullett, B.K. Proceedings of the Second International Conference on Managing Hazardous Air Pollutants, 13-15 July: Washington, D.C., USA, 1993

(12) Otani, Y.; Emi, H.; Kanaoka, Ch.; Uchijima, I.; Nishino, H. Environ. Sci. Technol. 1988, 22, 708-711.

(13) Serre, S.D.; Silcox, G.D. Ind. Eng. Chem. Res. 2000, 3, 1723-1730.

(14) Carey, T.R.; Richardson, C.F.; Chang, R.; Meserole, F.B.; Rostam-Abadi, M.; Chen, S. Environ. Progr. 2000, 19, 167-174.

(15) Pavlish, J.H.; Sondreal, E.A.; Mann, M.D.; Olson, E.S.; Galbreath, K.C.; Laudal, D.L.; Benson, S.A. Fuel Proc. Technol. 2003, 82, 89-165.

(16) Sloss, L.L. Mercury emissions and effects-The role of coal. IEAPER/19. IEA Coal Research, 1995; pp 39.

(17) Li, Z.; Luo, X.; Hwang, J.Y. J. Min. Mat. Cgara. Eng. 2002, 1, 79-96.

(18) Karatza, D.; Lancia, A.; Musmarra, D. Environ. Sci. Technol. 1998, 32, 39994004.

(19) Hower, J.C.; Maroto-Valer, M.M.; Taulbee, D. N.; Sakulpitakphon, T. Energy Fuels. 2000, 14, 224-226.

(20) Hower, J.C.; Finkelmen, R.B.; Rathborne, R.F.; Goodman, J. Energy Fuels. 2000, 14, 212-216.

(21) ECSC Research project 7220-ED-095 “Removal of volatile toxic trace elements in flue gases from coal conversion. Final Report, 2001, pp 64.

(22) Gleen, A.; Norton, H.Y.; Brown, R.C.; Laudal, D.L.; Dunham, G.E.; Erjavec, J. Fuel. 2003, 82, 107-116. 
Table 1. Composition of synthetic gas mixtures used in the retention experiments $(\mathrm{v} / \mathrm{v} \%)$ and mercury concentration in gas phase $\left(\mu \mathrm{g} \mathrm{ml}^{-1}\right)$

\begin{tabular}{l|ccccccccc}
\hline & $\mathrm{CO}$ & $\mathrm{CO}_{2}$ & $\mathrm{H}_{2}$ & $\mathbf{O}_{2}$ & $\mathbf{S O}_{2}$ & $\mathbf{H}_{2} \mathbf{O}$ & $\mathbf{H}_{2} \mathrm{~S}$ & $\mathbf{N}_{2}$ & $\mathrm{Hg}$ \\
\hline Gasification & 64 & 3.7 & 20.9 & --- & --- & 4.0 & 1.0 & 6.4 & 0.40 \\
Combustion & --- & 15 & --- & 9.2 & 0.2 & 6.6 & --- & 69 & 0.40 \\
Inert & --- & --- & --- & --- & --- & --- & --- & 100 & 0.12 \\
\hline
\end{tabular}


Table 2. Mercury capture in different atmospheres in material of different unburned content and surface area

\begin{tabular}{|c|c|c|c|c|c|c|c|c|c|}
\hline \multirow[b]{3}{*}{ Sorbent } & \multirow[b]{3}{*}{$\begin{array}{c}\text { Surface } \\
\text { area } \\
\mathbf{m}^{2} \mathbf{g}^{-1}\end{array}$} & \multirow[b]{3}{*}{$\begin{array}{c}\text { LOI } \\
\%\end{array}$} & \multirow[b]{3}{*}{$\begin{array}{c}\text { ash } \\
\%\end{array}$} & \multicolumn{6}{|c|}{ Hg } \\
\hline & & & & \multicolumn{2}{|c|}{ combustion } & \multicolumn{2}{|c|}{ gasification } & \multicolumn{2}{|c|}{ inert } \\
\hline & & & & $\begin{array}{l}\text { MRC } \\
\text { mg g }^{-1}\end{array}$ & $\% E$ & $\begin{array}{l}\text { MRC } \\
\text { mg g }^{-1}\end{array}$ & $\% \mathrm{E}$ & $\begin{array}{l}\text { MRC } \\
\text { mg g }^{-1}\end{array}$ & $\% \mathbf{E}$ \\
\hline sand & ----- & --- & --- & 0.005 & --- & 0.003 & --- & --- & ---- \\
\hline CTP & 6.7 & 3.8 & & 0.74 & $3.2 \pm 1$ & 0.60 & $2.4 \pm 1$ & 0.57 & $2.2 \pm 1$ \\
\hline CTA & 1.6 & 5.7 & & 12.1 & $11 \pm 2$ & 0.35 & $2.6 \pm 1$ & 0.30 & $2.7 \pm 1$ \\
\hline CTSR & 9.4 & 7.2 & & 25.4 & $8.1 \pm 3$ & 3.94 & $12 \pm 3$ & 3.71 & $16 \pm 2$ \\
\hline CA & 310 & & 30 & 1.74 & $14 \pm 4$ & 1.86 & $14 \pm 1$ & --- & --- \\
\hline RB3 & 1183 & & 6.0 & 7.54 & $21 \pm 8$ & 7.66 & $24 \pm 6$ & --- & --- \\
\hline
\end{tabular}


Table 3. Elemental composition of the inorganic components of the fly ashes and activated carbons (\%wt)

\begin{tabular}{lccccc}
\hline & CTP & CTA & CTSR & CA & RB3 \\
\hline $\mathrm{SiO}_{2}$ & 52.1 & 53.3 & 55.3 & 9.36 & 1.70 \\
$\mathrm{Al}_{2} \mathrm{O}_{3}$ & 21.9 & 25.6 & 22.7 & 5.37 & 0.21 \\
$\mathrm{Fe}_{2} \mathrm{O}_{3}$ & 5.97 & 5.87 & 4.84 & 10.7 & 0.19 \\
$\mathrm{MgO}$ & 1.39 & 1.82 & 1.51 & 0.50 & 0.35 \\
$\mathrm{Na}_{2} \mathrm{O}$ & 0.63 & 0.72 & 0.62 & 0.11 & 0.15 \\
$\mathrm{~K}_{2} \mathrm{O}$ & 2.98 & 3.37 & 2.42 & 0.44 & 0.23 \\
$\mathrm{TiO}_{2}$ & $<1$ & $<1$ & $<1$ & $<0.30$ & $<0.05$ \\
$\mathrm{SO}_{3}$ & 5.12 & 0.31 & --- & 1.69 & 0.49 \\
$\mathrm{CaO}$ & 6.36 & 2.09 & 2.77 & 1.82 & 0.34 \\
\hline
\end{tabular}




\section{Figure captions}

Figure 1. Schematic diagram of the experimental device.

Figure 2. SEM micrographs of the fly ash samples from the coal-pulverized power plant (a) and from the fluidised bed boiler (b)

Figure 3. SEM micrographs of a particle altered (a) and of a particle unaltered (b) in the activated carbon CA

Figure 4. Mercury retention in fly ashes in the combustion atmosphere

Figure 5. Mercury retention in fly ashes in the gasification atmosphere

Figure 6. Mercury retention in fly ashes in the inert atmosphere 


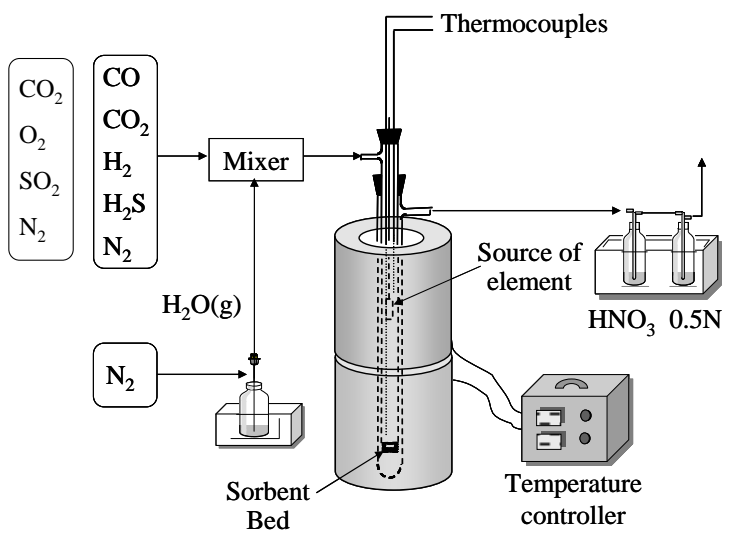

Figure 1. 


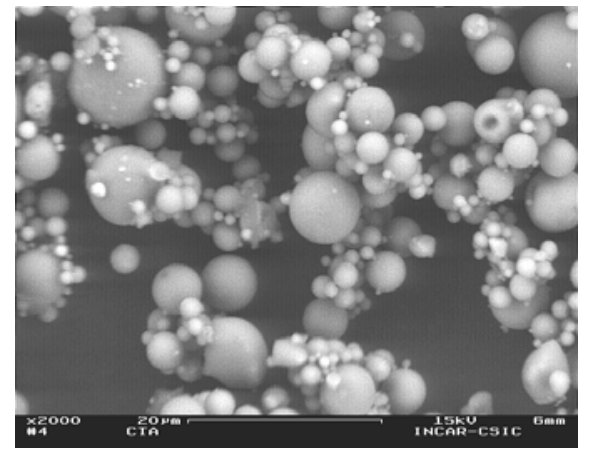

(a)

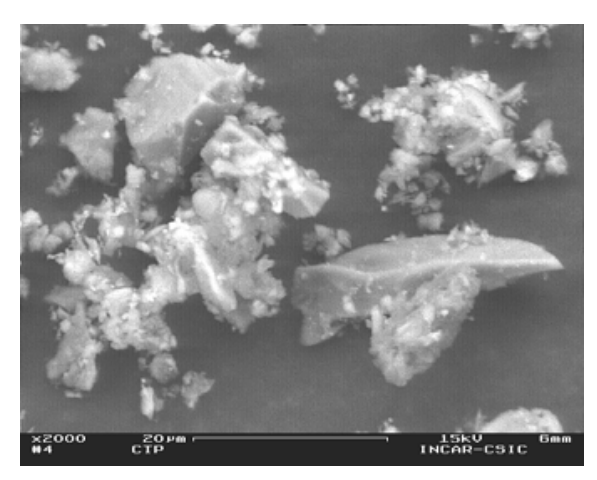

(b)

Figure 2. 


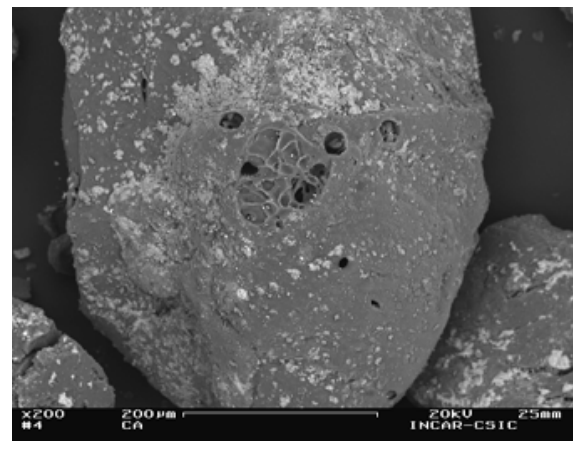

(a)

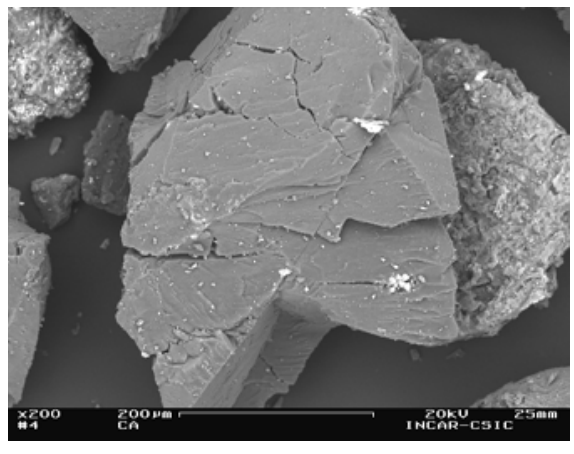

(b)

Figure 3. 


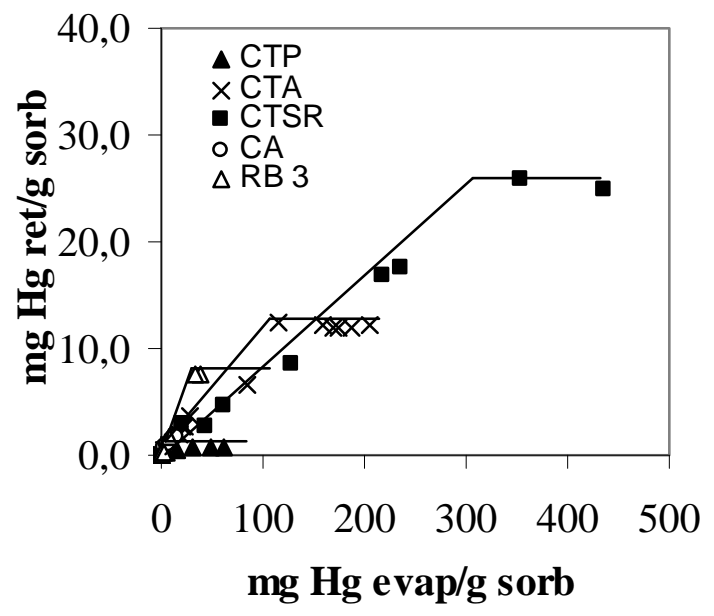

Figure 4. 


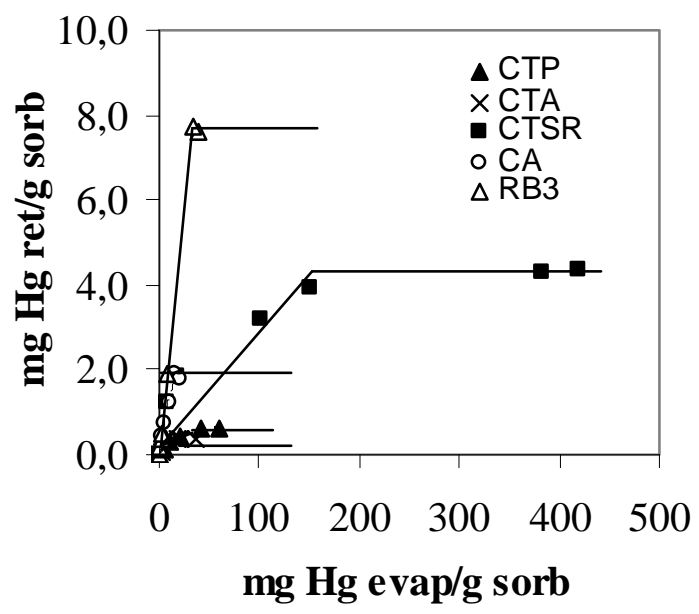

Figure 5. 


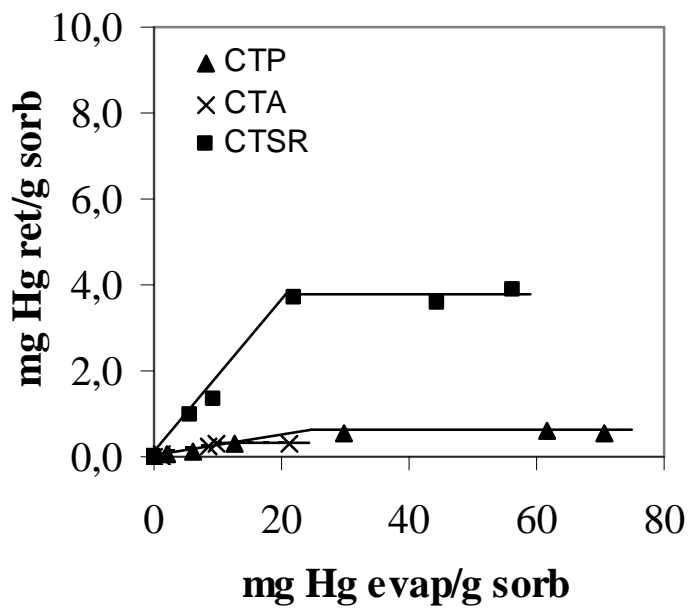

Figure 6 